\title{
FURTHER OBSERVATIONS ON THE THYROID GLAND (VI.).
}

\author{
By Walter Edinunds, F.R.C.S.
}

From the Laboratory of the Brown Institution.

\section{(Plates XVII. aNd XVIII.)}

THE question of the existence of secretory nerves to the thyroid gland was considered in a former paper, and certain experiments bearing on the matter were there related. ${ }^{1}$ As the point is of importance it has been thought advisable to make further experiments, with controls.

The experiments were made on dogs, and consisted in excising on one side from, at, above, or just below the point where the superior laryngeal nerve is given off from the vago-sympathetic a great length of both the superior laryngeal and the vago-sympathetic nerves. In this way any secretory fibres to the thyroid lobe coming by the cerebro-spinal nerves might be considered to be destroyed, but the operation would allow of secretory fibres reaching the lobe by way of sympathetic fibres accompanying the blood vessels; in addition to this, in many of the experiments the thyroid lobe of the opposite side was excised. By way of control, in other dogs, one thyroid lobe was simply excised.

To commence with the controls. In all, eleven of these experiments were made; none of the dogs had any symptoms in consequence of the operations; they remained quite well till they were destroyed to obtain the remaining lobe. This was done at periods ranging from forty-eight to two hundred and fifty-five days, with an average of ninety-three days.

In order to determine whether the lobe left in situ had undergone hypertrophy, the lobe first removed was weighed and examined microscopically, and the same was done with the second lobe on removal.

In two out of the eleven dogs the first lobe removed did not appear normal under the microscope, but showed changes identical with those described as compensatory hypertrophy. We will for the present put aside these two experiments, thus reducing the number to nine.

In four of these nine experiments the two lobes proved to be of the same weight, and in another they appeared to be of the same size; in one case the remaining lobe was lighter than the first, and in

1 Journ. Path. and Bacteriol., Edin. and London, 1903, vol. viii. p. 288. 
another case there is reason to think it was heavier' and finally, in two experiments there was no note as to weight. Thus it may be inferred that simple excision of one thyroid lobe does not, as a rule, produce any marked increase in the weight of the remaining lobe.

With respect to the microscopic changes found in the lobe that was left, in two out of the nine well-marked compensatory hypertrophy was found; in four slighter but undoubted changes existed, and in three no change was found. Thus it is to be inferred that, as a rule, slight but distinct compensatory hypertrophy occurs.

With respect to the parathyroid glands in the lobes that were left, there were no pronounced changes found; the experiments did not show the parathyroid definitely changing into thyroid tissue to compensate for the excised lobe.

In two of the experiments, as stated, the lobe first removed showed appearances of compensatory hypertrophy; in one of these the second lobe on removal was lighter than the first, and like it showed well-marked compensatory hypertrophy. In the other experiment there was no note as to the relative weight of the lobes, and the second lobe was normal under the microscope.

With respect to the operations in which one lobe had its nerve supply interfered with, in two dogs the opposite thyroid lobe was left intact in situ; no symptoms were produced by the experiments, and after the dogs were killed on the forty-fourth and forty-ninth day both lobes appeared of about the same size, and both lobes were normal under the microscope.

In nineteen of the paralysing experiments the opposite (normal) lobe was excised as part of the operation.

In five of the nineteen experiments the operation was followed by well-marked symptoms of athyroidea. Two of the dogs recovered, three died; in two of these there was some affection of one lung, but they had athyroidic synptoms, and to this I incline to attribute their death.

With respect to the weight of the lobes. In six of the experiments both lobes were weighed: in four cases they were of practically the same weight; in one case the remaining lobe was somewhat larger, and in another somewhat smaller than the first. In two of the cases, however, in which the first lobe appeared about normal, but was not weighed, the second lobe was distinctly enlarged; in one of these it was greatly enlarged, weighing 2.95 grms., - the weight of a lobe is generally about a gramme,- the lobe under the microscope appeared normal.

With respect to the microscopic appearances in four of the nineteen experiments, the first lobe removed showed "compensatory hypertrophy"; in two of these cases the second lobe, when obtained, showed the same appearances, and in the other two the second lobe was normal. It would seem, then, that in these two cases the 
operation had caused a return of the second lobe to normal (see Plate XVII. Figs. A, B, and C).

In the other fifteen experiments the first lobe removed was normal; in eleven of these cases the second lobe when removed was also normal; in two, slight compensatory hypertrophy was found; and in two other cases, which were fatal in seven and eleven days, there were seen thinning of the wall of the vesicles, and flattening of the secreting cells, with collapse of the walls of the vesicles (see Plate XVII. Figs. D and E).

Of the total nineteen cases of the paralysing operation, three died with symptoms attributable to athyroidea; two (which died on the seventh and eleventh day) with pneumonic complication; and one was killed on the sixty-second day, when much emaciated. Besides these three, two had symptoms from which they recovered; the remaining fourteen had no symptoms. Of the sixteen which lived, six were submitted to the removal of the remaining lobe on flom the fortyninth to the two hundred and fifty-sixth day, the average being the one hundred and thirty-fourth day.

They all had severe symptoms of athyroidea, from which they either died or for which they were killed in a few days. The other ten were simply killed to obtain the remaining lobe. This was done on from the fifty-second to the two hundred and ninety-third day, the average being the one hundred and thirty-ninth day.

These experiments, as far as they go, seem to show-

1. That the paralysing operation does have some effect, for of the nineteen operations no less than five had athyroidic symptoms, whereas, as was to be expected, none of the simple one-lobe excisions were followed by symptoms.

2. That although there is some effect, it is not, as a rule, so great as to render the lobe useless, or even nearly so, because the surviving clogs always had severe athyroidea when the "paralysed" lobe was removed.

3. With respect to microscopic changes, it is seen that in the nine simple one-lobe excisions with the first lobe normal, well-rnarked "compensatory hypertrophy" occurred twice in the second lobe; distinct but less pronounced hypertrophy three times; whereas, in the fifteen paralysing operations with first lobe normal, pronounced hypertrophy did not occur at all ; slighter hypertrophy occurred twice; the lobe remained normal in eleven cases; and in two flattening of the secreting cells with collapse of vesicles was found.

Thus it would seem that the paralysing operation does produce some effect both clinical and pathological, but not a great effect; and it must be inferred that the secretion of the thyroid gland is due mainly to a chemical stimulus acting directly on the secreting cells, or the nerve endings distributed to them, or through fibres which pass along the blood vessels with the sympathetic fibres. 
An additional reason for thinking that there are secretory nerves to the thyroid is that such nerves are described and figured by Andersson, 1894, and also by Berkley, 1894. Further, the clinical history of cases of Graves's disease suggests an influence of the cerebrospinal system on the thyroid gland.

In quite a number of cases is there a history of fright, or nervous shock, acting apparently as an exciting cause. One of the eight cases in Parry's, 1825, classical paper is that of a girl, æet. 21 years, who was thrown out of a wheel chair when coming fast down-hill; the symptoms came on within a week or two. There is also some resemblance between the symptoms of Graves's disease and the manifestations of great anxiety.

Swale Vincent and Jolly, 1904, published a series of numerous experiments they had made on the thyroid gland; among other results they found that the complete removal of the thyroid from guineapigs was attended by no ill results. I have recently made similar experiments with a similar result.

In the goat, too, the removal of the thyroid is not followed by any ill effects. In four experiments I have removed the whole of the thyroid from the goat, and the animals remained quite well. It is this immunity from ill effects that has led to the milk or blood serum of a thyroidectomised goat being used in the treatment of Graves' disease.

Chalmers Watson (1904) has published some experiments on the effect of a meat diet on rats; he found that their growth was retarded, and in ten out of twelve experiments he also found microscopic changes in the thyroid gland.

I have made somewhat similar experiments on white rats, feeding them on very much underdone meat, and the control rats on bread and water. The results were (1) that the meat-fed rats were smaller, that is to say, their growth had been retarded, for they were not fully grown at the commencement of the experiment; (2) that their coats were rougher; (3) that their coats were not so clean as those of the controls; and (4) that they seemed less intelligent. I failed to satisfy myself as to any definite change in the thyroid under the microscope.

Chalmers Watson (1904) has also made some interesting experiments on feeding fowls on raw meat. Among other changes he found the thyroid and parathyroid glands much enlarged, in one experiment enormously enlarged. The microscopic changes in the thyroid proper consisted of (1) an increase in the size of the vesicles; (2) an increased thickness of the walls of the vesicles; and (3) a disappearance of the intervesicular glandular tissue. This enlargement of the vesicles without any convolution resembles that which occurs in simple human goitre (see Plate V. Fig. 13 in volume v. (1889) of this Journal); it also resembles the changes 
occurring sometimes after the "paralysing" operation on thyroid (see this paper, Plate XVII. Fig. E).

\section{REFERENCES.}

1. Parry . . . . . "Medical Writings," London, 1825, vol. ii. p. 114.

2. Andersson. . . . . . Archiv f. Anat. Physiol. u. wissensch Merl.; Leipzig, 1894, Anat. Abth., S. 177.

3. Berkley . . . . . . Johns Hoplins Hosp. Rep., Baltimore, 1894, vol. iv. p. 113.

4. Vincent, S., And Jolly . Journ. Physiol., London, 1904, vol. xxxii. p. 65.

5. Watson, D. Chalmers. . Med. Chir. Trans., London, 1904, vol. lxxxvii. p. 531; Lancet, London, 1906, vol. ii. p. 1778 .

6. Forsyth, David . . . . "Observations on the Human Parathyroid Glands," Journ. Physiol., London, 1906, vol. xxxv. p. 1.

7. Thompson-Gilman . . . "Eighty Cases of Exophthalmic Goitre," Am. Journ. Med. Sc., Phila., 1906, vol. exxxii. p. 835.

8. West, Samuel M. D. . . "Severe Case of Exophthalmic Goitre, with Acute Myxœedema," St. Barth. Hosp. Rep., London, 1906, vol. xlii. p. 9.

\section{DESCRIPTION ȮF PLATES XVII. AND XVIII. \\ Plate XVII.}

Fis. A.-Section of thyroid and parathyroid, removed from an apparently normal dog. The small vesicles in the parathyroid will be noticed. $(\times 45 .)^{1}$

FIs. B. - Portion of the same thyroid lobe as shown in Fig. A, more highly magnified. It will be seen that there is a certain amount of convolution of the lining membrane of the vesicles, and that the secreting cells are columnar; there was colloid in the vesicles. $(\times 75$.

Fifr. C. - From the same dog as Figs. A and B. On the right side of the neck of the dog the superior laryngeal nerve and a considerable length of the vago-sympathetic nerve were removed, as described in the text; the left thyroid lobe was also removed. No ill effects were produced by the operation. The dog was killed on the one liundred and sixth day, and the right thyroid lobe obtained, and is here figured. It will be seen that the vesicles are larger than in the lobe first removed; the convolution of the lining membrane is absent, and the secreting cells are flatter. There was a certain amount of colloid. $(x 75$.

FiG. D.-Portion of the left lobe of the thyroid of an apparently normal dog. The thyroid. appears normal, and contained abundant colloid. On the right side of the neck of this dog the superior laryngeal nerve and a considerable length of the vago-sympathetic were excised, as described in text; the left thyroid lobe was also excised. The dog quickly became ill; he lost flesh, had muscular tremors, and a marked defect in gait; also great difficulty in breathing. On account of these symptoms he was killed on the eleventlı day. There was found inflammation of a portion of one lung. The right (remaining) lobe of the thyroid was removed and examined microseopically (see Fig. E). ( $\times$ 75.)

\footnotetext{
${ }^{1}$ Compare with Fig. 10, Tourn. Path. and Bacteriol., Edin. and London, 1900, vol. vi. p. 71. This parathyroid would pass for one changing into thyroid proper.
} 
FI(x. E. - It shows various changes. (1) Enlargement of vesicles; (2) absence of young resicular tissue between the full-sized vesicles; (3) walls of vesicles very thin, and flattening of secreting cells: the vesieles contained colloid. ${ }^{1}(\times 75$.

\section{Plate XVIII.}

FIG. F.-Paratly yroid from thyroid lobe of guinea-pig. $(\times 200$.

Fis. G. --Parathyroid of goat. It will be noticed that it is embedded in the substance of the thyroid, and is continuous with the thyroid vesicular structure.

As in the former papers, all the drawings are by Mr. Lapidge.

I Compare this figure with that from a human goitre, Journ. Path. and Bacteriol, 1899, vol. v. Plate V. Fig. 13. 


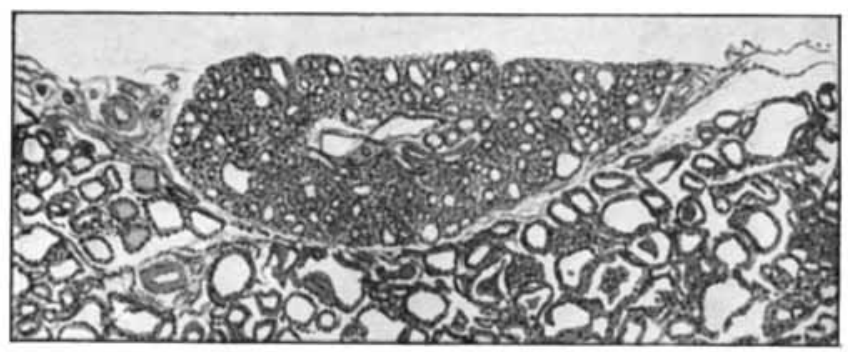

A.

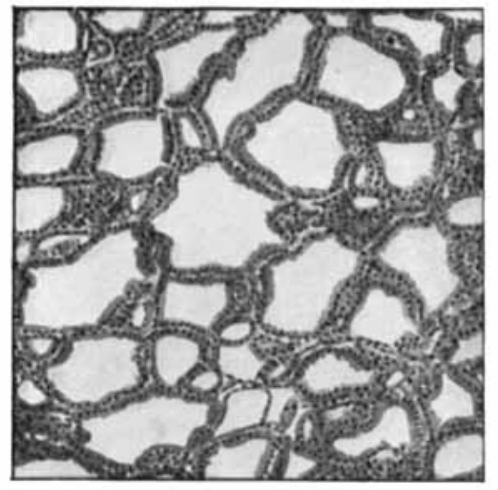

B.

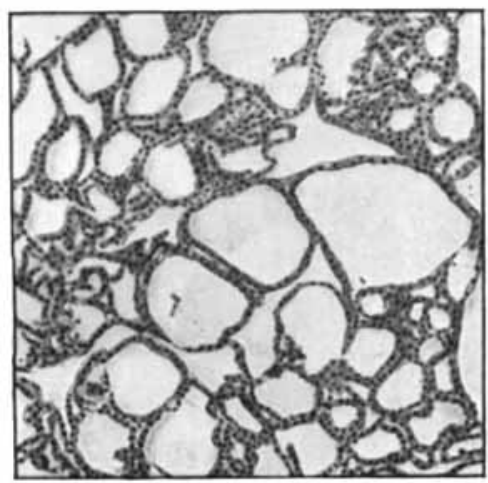

D.

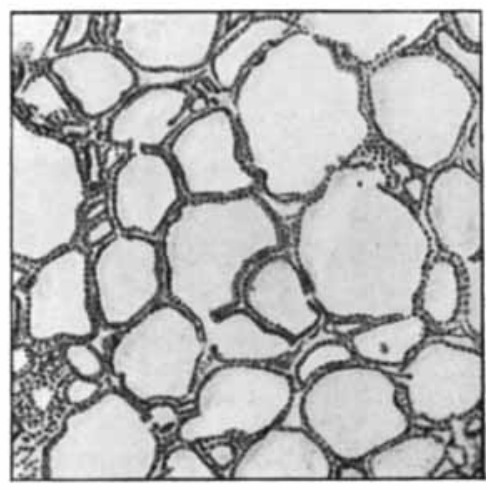

C.

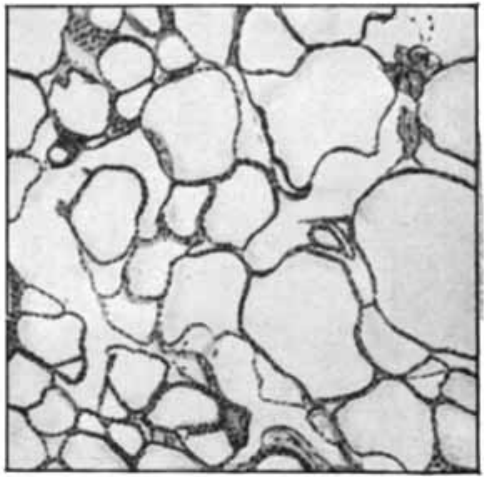

E. 


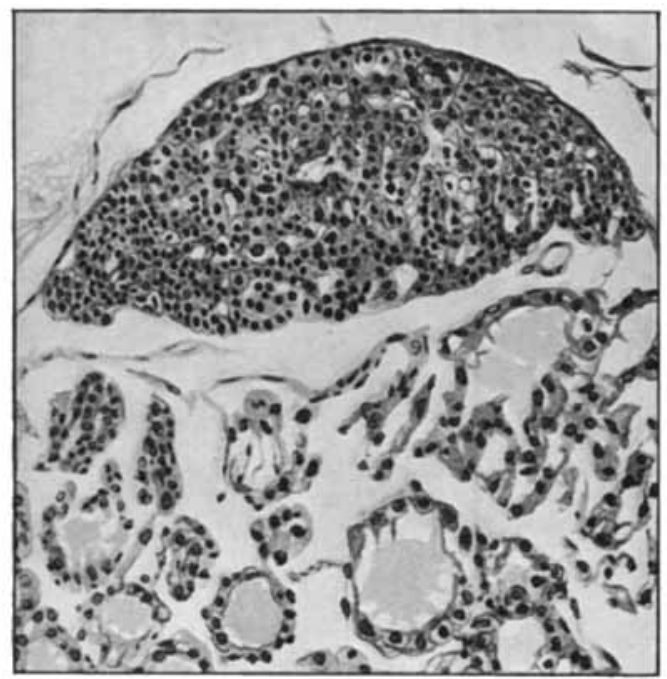

F.

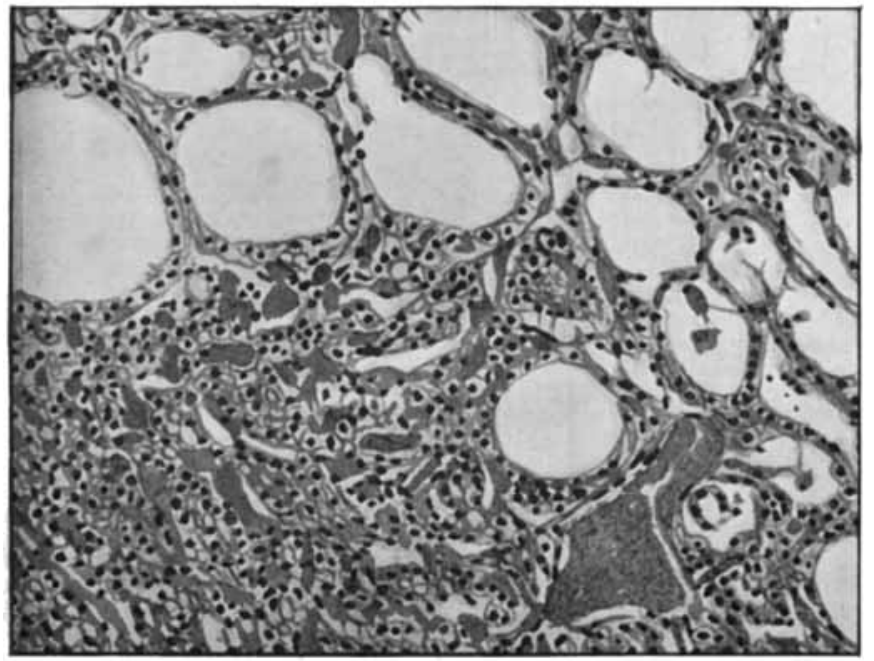

G. 